"Brain Drain and Institutions of Governance:

Educational Attainment of Immigrants to the US 1988-2000”

BY

James T. Bang
and
Aniruddha Mitra

November 2009

MIDDLEBURY COLLEGE ECONOMICS DISCUSSION PAPER NO. 0919

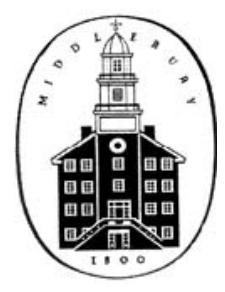

DEPARTMENT OF ECONOMICS

MIDDLEBURY COLLEGE

MIDDLEBURY, VERMONT 05753

http://www.middlebury.edu/ econ 


\title{
Brain Drain and Institutions of Governance: Educational Attainment of Immigrants to the US 1988-2000
}

\author{
James T. Bang \\ Department of Economics \\ Virginia Military Institute \\ 342 Scott Shipp Hall \\ Lexington, VA 24450 \\ bangjt@vmi.edu \\ Aniruddha Mitra \\ Department of Economics \\ Middlebury College \\ Warner Hall 502B \\ Middlebury, VT 05753 \\ amitra@middlebury.edu
}

\begin{abstract}
We use a fixed effects panel data model to investigate the impact of institutions of governance on the educational attainment of immigrants to the United States over the period 1988 - 2000. Distinguishing between the quality and stability of political institutions in the countries of origin, we find that the two characteristics of institutional structure have conflicting impacts on the nature of brain drain. Immigrants from countries with a higher quality of political institutions tend to be better educated, on the average, than immigrants from countries with institutions of lower quality. However, immigrants from countries with greater political instability tend to be better educated than immigrants from countries with more stable governments.
\end{abstract}

Keywords: Immigration, institutions, political instability, brain drain

JEL Codes: F22, J24, J61, J64 
We are grateful to the VMI Research Labs, Nicole Simpson, Linnea Polgreen, Salim Rashid, Robert Prasch, and seminar participants at VMI and the University of Illinois for comments and advice. All remaining errors are, of course, our own. 


\section{INTRODUCTION}

Immigration is a central theme in the globalization debate. Among the questions that have arisen in the discussion are: (1) what is the impact of immigration on welfare for the source and destination countries, and; (2) what are the distributional consequences of immigration for various interest groups? While most studies agree that there are net (but small) welfare gains for natives, the distributional question depends on many factors. One of these factors is whether or not the skill distribution of immigrants is representative of the distribution of skill in their respective home countries, or if immigrants are self-selected with some positive or negative skill bias. Because of its impact on the income distribution, selection bias may play a role in the politics of immigration policy.

The theoretical work on the selection of immigrants leaves the issue as an empirical question, and existing empirical tests have been inconclusive. The consensus is that the direction and magnitude of the selection bias depends on the conditions in the immigrants' home countries. This paper aims to complement the literature on immigrant selection bias. We find empirical evidence in support of the hypothesis that immigrants to the U.S. are favorably selected. We also find that favorable selection is stronger for immigrants who come from countries with more corrupt governments, who travel farther to get to the U.S., and whose home countries have higher average levels of educational attainment. The remainder of the paper is organized as follows: Section 2 reviews the literature on the selection and educational attainment of immigrants; Section 3 presents the empirical model and outlines the estimation methodology; Section 4 discusses the data; Section 5 explains the results, and; Section 6 concludes. 


\section{RELATED LITERATURE}

At a theoretical level, the cornerstone of the immigration literature is Mundell (1957), who predicts negative selection using a factor-endowments approach. Skill-abundant countries will receive mostly low-skill workers as a complement to comparative advantage through trade in factors. However, Chiswick (1978; 2001) predicts positive selection using a human capital model in which migrants compare the returns from migration to its moving and opportunity costs. Borjas (1987) finds that both patterns are possible using the Roy (1951) model of occupational selection. The theoretical literature on brain drain, such as Chakraborty (2006) and Docquier and Rapoport (2003), predicts positive selection and deserves mention for explaining immigration from countries with poor institutions, corruption, or discrimination.

There has also been considerable debate in the empirical literature about the average skill level of immigrants to the United States. For our purpose, three sets of findings stand out: (1) Borjas (1999) and Betts and Lofstrom (2000) find a negative trend in the skill level of immigrants relative to the native U.S. population over the 1970s and 1980s; (2) Cohen, Zack and Chiswick (1997) and Barrett (1996) find that the decreasing trend in immigrant skill level over the 1970s ended by the mid-1980s, and; (3) Polgreen and Simpson (2006) confirm the trends found in the previous studies above using data from 1972-2000, but find that the upward trend that began in the mid-1980s reverted to a decline by 1994. For a more comprehensive survey of the empirical literature on immigrant self-selection, we refer the reader to Borjas (1994).

Polgreen and Simpson (2006) is an important launching point for this study because it covers the most comprehensive sample period and offers a technique for measuring the education levels of immigrants in the years they arrived. Previous studies measured immigrant education by using census data for the education of the foreign born population living in the U.S. or by using wages 
as a proxy. Neither of these measures directly addresses the issue of immigrant selection at the time they arrive.

\section{EMPIRICAL MODEL AND ECONOMETRIC STRATEGY}

The specification of the empirical model is a straightforward extension of the model in Polgreen and Simpson (2006), which includes immigrant type, visa class, and region to explain the variation in the education of immigrants over time. They are able to attribute the trends in immigrant selection to three sources: (1) changes in the education and visa status of nonimmigrant residents; (2) policy changes, and; (3) demographic changes in immigrants' countries of origin.

Our goal is to investigate their third conclusion in greater detail to try to identify the country characteristics that affect the education of immigrants to the US. Specifically, we plan to evaluate whether the selection of immigrants is influenced more by the institutions and educational endowments in their countries of origin, or by the moving costs of immigrating relative to the benefits.

The model we estimate is:

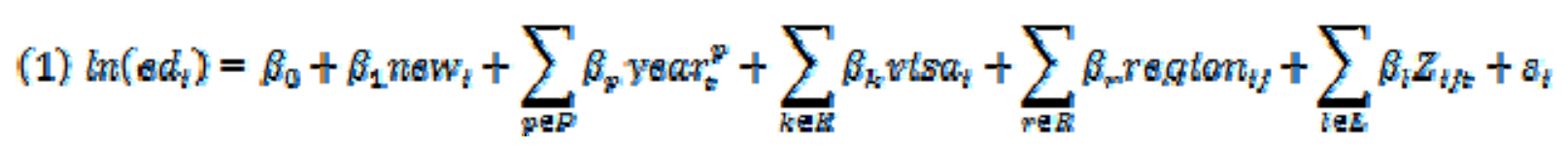

where new is a dummy variable indicating whether the visa is being issued to a new entrant; $\sum_{p a D} \beta_{p} y \in a x_{*}^{p}$ is a time-trend polynomial chosen to approximate the trend in immigrant skill over time observed by the existing literature; visa is a set of dummy variables for the 
immigrants' visa class (family, employment, refugee, diversity, Immigration Reform and Control Act, or "other"); region is a set of region-of-origin dummy variables, and; $Z$ are the country characteristics we are interested in. The details of these variables will be described in more detail in the next section.

We will employ a quantile regression as our estimation strategy to try to capture how the impacts of the variables vary for different levels of the distribution. Quantile regression estimates the treatment effects at a given quantile of the distribution by minimizing a weighted sum of the absolute deviations. Specifically, quantile regression solves:

\section{(3) $\min _{\beta}\left\{\tau(y-X \beta)-\left[E\left(a \alpha_{n} 0\right)(y-X \beta)\right]\right\}$,}

where $\tau \in(0,1)$ is the selected quantile and $I(*)$ is an indicator function equal to one if the error term, $y-X \beta$, is negative. A summary of this strategy can be found in Koenker (2005).

Quantile regression is useful because the explanatory variables of interest may have different marginal effects for observations in the tails of the distribution of immigrants than they do at the center. Quantile regression allows us to measure these differences without making restrictive assumptions. Also, quantile regression helps account for individual heterogeneity that cannot be easily corrected using instrumental variables (Arias et al. 2001). There are also economic reasons that quantile regression is useful for describing the skills of immigrants. First, the theories about selection have more to do with how variables affect skill selection in the tail of the distribution. Secondly, estimating the conditional quantile helps account for the fact that education may be a "lumpy" investment, in that individuals “drop out” after well-defined intervals.

\section{DATA}

For the sample period 1988-2000, data for immigrants to the U.S. come from "Immigrants Admitted to the United States” published by the Immigration and Naturalization Service (INS). 
Immigrant characteristics in this dataset are: year of admission; visa class; countries of birth, last residence, and quota chargeability; age; occupation; marital status; gender; type (new admission or a visa adjustment non-immigrant foreign residents); intended US state and city of residence, and; labor certification status.

The INS data does not directly report immigrants' education levels, so we adopt the data constructed by Polgreen and Simpson (2006), who estimate immigrants' education based on their occupation and other characteristics in the INS dataset. Using data for U.S. natives from the Current Population Survey (CPS), they estimated the following equation for each occupation, $k$ :

\section{(4) $\overrightarrow{a a_{t k}}=\beta_{0}+\beta_{1} a g Q_{t k}+\beta_{2} g a n d a r_{t k}+\beta_{a} \operatorname{marrtad}_{t b e}$.}

The goal of constructing the education variable this way is to capture the variations in educational attainment caused by variations in observed characteristics.

This measure of immigrant education has disadvantages, which are discussed in Polgreen and Simpson (2006), and which we will summarize here. First, it only measures the education of immigrants who report a useful occupation. Immigrants who are children, retirees, students, unemployed, homemakers, or do not report an occupation comprise about $65 \%$ of the immigrants who entered during the sample period. Fortunately, these numbers have been relatively stable over that time so any bias that their omission may introduce is not fluctuating much. Secondly, immigrants are less likely to be matched into their primary occupation than natives. This may be related to licensing and other entry barriers. Chiswick (2008) finds that immigrants have a flatter distribution of wages across different skill levels, and partly attributes this to occupational mismatching. However, while skill mismatching may affect immigrants' wage distribution after they arrive, it does not necessarily reflect on their ability when they decided to leave home. Econometric problems with constructed variables include measurement error described by 
Bollinger and Hirsch (2006). This may not seriously impact the elasticities we estimate as long as the bias is proportional to the actual levels of education.

Despite these shortcomings, we feel that the INS data still give the best snapshot at the time of arrival and therefore did a better job of addressing our main question. Some studies look at immigrants' occupations, wages and education levels using the CPS. While using the CPS might overcome some of the difficulties described above, it too is flawed because the CPS does not provide information about the characteristics of immigrants when they arrived and therefore does not answer the selection question. The CPS also includes undocumented immigrants, whose selection may be distorted by other factors. ${ }^{1}$

Summary statistics of the education variable are reported by country in Table 1. Columns (1) through (3) show the region, country, and number of immigrants from each country. The headcounts show that the countries which sent the most immigrants during this period were Mexico, The Philippines, and India. However, since the dataset deals specifically with legal immigration, it is not dominated by any single country or geographic region. This is because since 1965 U.S. immigration policy has set a single aggregate quota for the world, with a uniform percentage cap for the total from any single country. ${ }^{2}$ Columns (4) through (7) report the mean, standard deviation, maximum and minimum values for the constructed education variable for immigrants from each of the countries. The last two columns of Table 1 show the average educational attainments of these immigrants' countries of origin in 1960 and 2000, respectively. Comparing these figures to column (4) of the table suggest that, while there may have been a downward trend in the education of immigrants at certain times during the sample period, it is

\footnotetext{
${ }^{1}$ For example, illegal immigrants may be selected because they have less to lose from being barred legal entry for life and thus tend to be lower-skilled.

${ }^{2}$ Quota exceptions include: (1) refugees, and; (2) the Western Hemisphere. Immigration from the Western Hemisphere had not fallen subject to quotas before 1965when a quota was added at a level of twice the quota allocated to the rest of the world.
} 
unlikely that there was ever negative selection relative to the distribution of skill in immigrants' home countries.

The first group of explanatory variables we choose to include in our estimation of equation (1) are: type of case (new or adjusted), region of origin, visa class, and year from the INS dataset. Type of case is a dummy variable equal to one for new immigrants and zero for adjustments in the visa status of foreign residents already in the United States. Regions are included as dummy variables for immigrants coming from Western Europe, Eastern Europe, Asia, Africa, Oceania, and South America, leaving North America and the Caribbean as the benchmark group. Visa class includes dummy variables for family members of U.S. residents, ${ }^{3}$ employment visas, ${ }^{4}$ legalized status under the 1986 Immigration Reform and Control Act (IRCA), ${ }^{5}$ "diversity" visas, ${ }^{6}$ and "other" visas, ${ }^{7}$ with refugees serving as the benchmark group. We also included polynomial function of the year the visa was issued to approximate the changes in the trends of immigrant education described in previous studies.

We then add several country characteristics. They are: population and real per capita gross domestic product (GDP) from the World Bank World Development Indicators (WDI); the corruption index from the International Country Risk Guide (ICRG); distance and dummy variables for English-speaking countries and countries with a shared colonial history with the US from the Centre d'Etudes Prospectives et d'Informations Internationales (CEPII), and; average educational attainment in each immigrant's home country from Barro and Lee (2001). Because of limited availability of the ICRG and education data for several countries, the final sample consisted of about 1.8 million legal immigrants between 1988 and 2000.

\footnotetext{
${ }^{3}$ Using the 29 classifications in the 2000 INS dataset, family visas included classifications 1-4, 14-18, and 21.

${ }^{4}$ Classifications 5-9.

${ }^{5}$ Classifications 22, 26, and 27.

${ }^{6}$ Classifications 13 and 23.

${ }^{7}$ Classification 29.
} 
The variables we are most interested in are corruption, distance, and educational attainment in the immigrants' countries of origin. Corruption is included to determine how poor institutions in developing countries influence the problem of brain drain and is predicted to have a positive impact on immigrant education. Next, it is predicted that distance variable will not only reduce the quantity of immigrants in the context of "gravity," but it will also improve the quality of immigrants. ${ }^{8}$ Chiswick (2000) predicts that higher moving costs will lead to favorable selection and rule out negative selection. Finally, average education in each immigrant's country of origin is used to measure that country's endowment of skilled labor relative to unskilled labor, which may impact the returns to human capital in that country and the incentives to emigrate. Mundell (1957) and Borjas (1987) predict immigrants from countries with more skilled workers will be better-educated in both absolute and relative terms. Summary statistics for all explanatory variables are reported in Table 2.

\section{RESULTS}

In this section, we highlight the empirical findings from: (1) OLS regression, to get an idea of the marginal effects around the mean, and; (2) quantile regression, to show how those impacts may vary at different levels of the skill distribution and; (3) ordered probit regression, to test the sensitivity of the results to small errors in the measurement of the education variable.

\section{$\underline{\text { OLS Results }}$}

OLS estimation results for several specifications of equation (1) are reported in Table 3, with standard errors in parentheses. The specification in column (1) excludes country characteristics, Z. These results are consistent with Polgreen and Simpson (2006) in the sense that there is

\footnotetext{
${ }^{8}$ The relationship between trade cost and value is one common to the literature on trade in goods and services. A review by Leamer (2006) discusses various concepts of geography in economics in the context of Thomas Friedman's popular notion of "flatness."
} 
similar variation on the basis of visa class, region, and type, and the time-trend displays similar breaks as those documented in their analysis.

OLS estimates including country characteristics, $Z$, appear in columns (2) and (3) of Table 3. Column (2) includes only the control variables of GDP, population, language and colonial history variables and column (3) includes these characteristics as well as the corruption, distance and country of origin education variables we are interested in testing. Comparing these specifications the year, visa, and regional variables we see that there is not much change in the signs or magnitudes of their coefficients across specifications. The only place that we do notice some change is in the regional dummy variables, but these changes are not unexpected since distance and institutional quality are similar among geographic neighbors and political friends. The coefficients on the country control variables are virtually unchanged when we add corruption, distance and education in the country of origin.

Finally, column (4) shows the results from running OLS on equation (1) excluding the linear term of the polynomial time trend. The reason for including this specification is that quantile regression does not lead to an analytical solution, and therefore is both less stable and more sensitive to correlations among the explanatory variables than OLS is. Estimating equation (1), quantile regression was forced to drop the year variable. There are virtually no differences in the variables of interest between columns (3) and (4). Therefore, the rest of this subsection will focus on the results in Table 3, column (4).

The first group of country characteristics is the group of variables that control for population, GDP per capita, and dummy variables for English-speaking countries and countries that share a common colonial history with the United States. They tell us that immigrants from countries with historically large populations that speak English are more educated, while immigrants from 
countries whose populations have grown most, have the higher GDPs per capita, and which share a colonial history with the United States are less educated.

The coefficients on the corruption index, distance, and average educational attainment variables reveal that: (1) immigrants from more corrupt governments are better-educated; (2) moving costs improve immigrant quality, and; (3) immigrants from countries with higher education levels are themselves better educated. However, there is no evidence that this rises to the level of "positive selection" on the basis of skill endowments or the returns to human capital.

The corruption index's coefficient tells us that countries with higher levels of corruption in government send more educated immigrants to the United States. As a result, a one-point worsening in a country's ICRG corruption index will result in immigrants to the U.S. who are $11.3 \%$ more educated, on average. In years, a one standard deviation change in the corruption levels in a country will increase the expected educational levels of its immigrants by about 0.29 years. This result is consistent with the Docquier and Rappaport (2003) model of skilled migration. The sign of the distance variable is also positive and significant. Although the magnitude its elasticity is small (0.038), it is not of lesser importance. A one standard deviation change in the distance from the U.S. leads to about a 0.37 year increase in immigrants' education, which is more than the impact of corruption. This result supports the predictions of models involving moving costs, which include Chiswick (2000) and Borjas (1987).

The impact of education in immigrants' countries of origin is more complicated. Increases in a country's current average level of education increases the quality of its immigrants, even when controlling for 1960 educational attainment rates. The elasticity for country of origin average education in 1960 was about -0.007 , meaning that slightly less-educated immigrants to the U.S. came from countries with higher initial education levels. At the same time, the elasticity of current educational attainment was estimated to be about 0.03 . This shows that better-educated 
immigrants came from countries with higher current educational attainments and improvements in educational attainment rates since 1960. However, neither of these results supports the notion that immigrants from countries with higher skill endowments are positively selected. To determine this, we must test whether this elasticity is greater than one, which cannot be rejected. Therefore, even if negative selection from low-skill countries is possible, it seems unlikely that it follows the pattern described in Mundell (1957) or Borjas (1987).

\section{$\underline{\text { Quantile Regression Results }}$}

The next step is to see how the marginal impacts of these variables vary throughout the distribution and then see what the predicted values from the quantile regressions show about the distribution of immigrants' skills. The Table 4 shows the estimated quantile coefficients for selected quantiles ( $\tau=0.05,0.25,0.50,0.75$, and 0.95 ) with standard errors in parentheses. This table tracks the changes in the impacts of various factors and the statistical significance of those factors at different quantiles. For example, 1960 educational attainment in an immigrant's country of origin stands out because its impact is significantly positive (0.011) for immigrants in the $5^{\text {th }}$ percentile but significantly negative $(-0.036)$ for immigrants in the $95^{\text {th }}$ percentile. For other variables, the coefficients do not change in sign or significance, but nonetheless vary substantially, as corruption does $\left(0.024\right.$ at the $5^{\text {th }}$ percentile and rising to 0.169 at the $\left.95^{\text {th }}\right)$.

Figures 1 through 4 illustrate the variations in the coefficients for the four variables of interest (corruption, distance, average education, and average education in 1960) more clearly. In each figure the solid black line connects the observed values of the estimated quantile regression coefficients at every fifth percentile between the $5^{\text {th }}$ and $95^{\text {th }}$. The smooth, grey curve fits a sixthorder polynomial trendline to the estimated quantile coefficients, and the horizontal dashed line references the OLS estimate. Confidence interval bands are not included because the standard errors are extremely small and the lines are almost indistinguishable. 
First, Figure 1 shows the quantile regression coefficients for the corruption index in the immigrant's country of origin across quantiles. It shows that the impact of corruption is relatively weak for lower-skilled immigrants, but progressively stronger for immigrants at higher skill levels. This strengthens the case supporting models related to brain drain and institutions.

Next, Figure 2 plots the elasticity of distance on immigrants' education levels across quantiles. Moving costs improve the overall quality of immigrants at all skill levels, but its importance is less for low-skill immigrants. The upward trend in the value of the estimated coefficient is fairly consistent beginning with a value of 0.004 at the $5^{\text {th }}$ percentile, and rising above 0.052 at the $95^{\text {th }}$. While this generally confirms theoretical predictions about the impact of moving costs, it is unclear why these costs would impact higher skill levels more than lower ones. One explanation is that for low skill immigrants living Mexico or other Latin American countries, waiting for the opportunity to migrate legally has a high opportunity cost. Instead of waiting, they can obtain similar benefits by exploiting legal seasonal opportunities in border communities that do not require a visa, or by immigrating illegally. These immigrants are not captured by the INS data.

Finally, Figures 3 and 4 show the effects of education levels in the immigrant's country of origin. Figure 3 graphs the coefficient for the elasticity of the 1960 average educational attainment in an immigrant's country of origin. It shows a declining trend and a reversal in sign for this coefficient across quantiles, starting at 0.011 at the $5^{\text {th }}$ percentile and falling to -0.035 at the $95^{\text {th }}$. The OLS coefficient falls in between at -0.007 . Figure 4 shows the quantile regression coefficients for average years of education in the immigrant's host country. In contrast to the previous three figures, this coefficient does not display a dominant upward or downward trend over the quantiles of immigrant skill. Also, the sign its impact is negative (and significant) for low skill levels (about -0.016), before becoming positive at about the $15^{\text {th }}$ percentile, and 
remaining positive for middle and higher skill immigrants. The size of the impact of education peaks at a value of 0.058 in the $60^{\text {th }}$ percentile of immigrant skill before falling to about 0.010 at the $95^{\text {th }}$ percentile.

\section{Robustness}

The question next we ask is: How sensitive are the patterns described above slight changes in how we define the dependent variable? What if the education of a native-born construction worker poorly reflects the education of an immigrant construction worker? Are the marginal effects and trends described in this section still valid? To answer this, we converted the constructed education variable into a categorical variable with five different skill groups. These five skill categories are: (1) 11 or fewer constructed years of education; (2) between 11 and 13 constructed years of education; (3) between 13 and 15 constructed years of education; (4) between 15 and 17 constructed years of education, and; (5) more than 17 years of constructed education. The result is a variable that assigns individuals into broad skill classifications that mostly reflect their occupational selection. ${ }^{9}$ Across the bottom row of Table 5 we report the number of immigrants who fall into each of the skill groups below each group's marginal effects coefficients.

Categorizing the estimated skill will sort them mostly on the basis of occupation and make the results less sensitive to small discrepancies in education levels across immigrants from different countries or the choice of conditioning variables used in its construction. Since we control for most other attributes, the only reason this approach should be a problem would be if the ordering of occupations on the basis of skill differed greatly across countries. In other words, the fact that German and Chinese engineers and construction workers have different absolute

\footnotetext{
${ }^{9}$ We could have simply subjectively assigned each occupation as "skilled" or "unskilled" and run a logit regression. In fact, this was one of our first experiments. The results were similar to those obtained from performing OLS on the constructed years of education.
} 
levels of education would not necessarily pose a problem, as long as engineers and construction workers are ranked similarly relative to other occupations in each country.

The coefficients in column (1) of Table 5 are the coefficients of the ordered probit regression using this measure categorical skill as the dependent variable. Comparing these results to column (3) of Table 3, there do not seem to be any differences that would seem to invalidate the basic conclusions from the OLS in terms of signs or significance levels. Columns (2) through (6) of Table 5 show the marginal effects of these variables throughout the distribution. In these columns the signs of the marginal effects are expected to vary some from the coefficients obtained in the quantile regression because the probabilities must sum to one (and therefore each set of marginal effects must sum to zero). Looking across the rows for corruption, distance, and educational attainment, the marginal effects follow similar patterns to those plotted in Figures 1 through 4. This suggests that measurement errors and bias introduced by the construction of the variable we use for immigrants' education are unlikely to be having extreme consequences for the qualitative nature of our results.

\section{CONCLUSION}

In the Mundell and Borjas-Roy models of immigration, higher skill endowments in the immigrants' country of origin lead to higher education levels for immigrants and even positive selection. Our results support the hypothesis that higher attainment rates produce a higher quality of immigrants, but this effect is not strong enough to support positive selection relative to the average non-migrant. This affirms the interpretation of the data offered by Jasso and Rosenzweig (1990). On the other hand, the human capital model advocated in Chiswick (2000) suggests that

moving costs play a more prominent role and that positive selection is the most likely outcome of migration. Our results are more consistent with these predictions. Moving costs such as distance, 
language, and colonial history did play an important role. Finally, our results offer strong support for the role of institutions in the quality of immigrants in a way that is consistent with models of brain drain and discrimination.

More importantly, this paper raises some new and important questions for the direction of research in the area. First, immigration policy and human capital investment choices may both play roles in explaining why negative self-selection is so unlikely. Introducing these factors as part of the decision sequence may shed light on the results we have found. Yet another question concerns welfare and income distribution for natives in the receiving country. While it is often presumed that stricter immigration quotas will foster positive selection and would therefore benefit natives more, the case for this is not clear cut, and the potential impacts of these policy choices on selection need to be investigated carefully. A third issue concerns welfare and development in poor countries, and the problem of brain drain. We have found evidence that immigrants from poorer countries are well-educated relative to those who do not migrate and this selection bias is magnified by poor institutions and low rates of overall educational attainment in those countries. This may pose an obstacle to development in these countries.

Our results generally agree with Polgreen and Simpson (2006), who show that much of the difference in the education of immigrants can be explained by changes in the countries of origin from which immigrants have come over time. We advance the literature by describing what some of those country characteristics are. 


\section{REFERENCES}

Arias, O., Hallock, K.. and Sosa-Escudero, W. (2001) Individual heterogeneity in the returns to schooling: instrumental variables quantile regression using twins data, Empirical Economics, 26, 7-40.

Bollinger, C. and Hirsch, B. (2006) Match bias in the earnings imputations in current population survey: the case of imperfect matching, Journal of Labor Economics, 24, 483-520.

Barrett, A. (1996) Did the decline continue? comparing the labor-market quality of United States immigrants from the late 1970's and late 1980's, Journal of Population Economics, 9, 55-63.

Barro, R., and Lee, J. (2001) International data on educational attainment: updates and implications, Oxford Economic Papers 53, 541-63.

Betts, J., and Lofstrom, M. (2000) The educational attainment of immigrants: trends and implications, in Issues in the Economics of Immigration, (Ed) G. Borjas, The Chicago University Press, Chicago, 51-115.

Borjas, G. (1987) Self-Selection and the Earnings of Immigrants, American Economic Review, 77, 531-53.

. (1994) The economics of immigration, Journal of Economic Literature, 32, 1667-717.

. (1999) Heaven's Door: Immigration Policy and the American Economy, Princeton, Princeton University Press.

Bratsburg, B. (1995) Legal versus illegal U.S. immigration and source country characteristics, Southern Economic Journal, 61, 715-27.

Chakraborty, B. (2006) Brain drain: an alternative theorization, Journal of International Trade and Economic Development, 15, 293-309.

Chiswick, B. (1978) The effect of Americanization on the earnings of foreign-born men, Journal of Political Economy, 86, 897-921.

- Are immigrants favorably self-selected? An economic analysis, in Migration Theory: Talking Across Disciplines, (Eds) C. Brettell and J. Hollifield, New York: Routledge, 61-76.

Chiswick, B., Le, A. and Miller, P. (2008) How immigrants fare across the earnings distribution: international analyses, Industrial and Labor Relations Review, 61, 353-73.

Cohen, Y., T. Zach, and B. Chiswick. "The Educational Attainment of Immigrants: Changes over Time,” Quarterly review of Economics and Finance, 37, 1997, 229-43.

Docquier, F. and Rapoport, H. (2003) Ethnic discrimination and the migration of skilled labor, Journal of Development Economics, 70, 159-72. 
Gang, I. and Rivera-Batiz, F. (1994) Labor market effects of immigration in the United States and Europe: substitution vs. complementarity, Journal of Population Economics, 7, 157-75.

Grossman, J. (1982) The substitutability of natives and immigrants in production," Review of Economics and Statistics, 64, 596-603.

Jasso, G. and Rosenzweig, M. (1990) Self-selection and the earnings of immigrants: a comment, American Economic Review, 80, 298-304.

Koenker, R. (2005) Quantile Regression, (Econometric Society Monographs, 38) Cambridge: Cambridge University Press.

Leamer, E. (2007) A flat world, a level playing field, a small world after all, or none of the above? A review of Thomas L. Friedman's "The world is flat," Journal of Economic Literature, 45, 83-126.

Melkumian, A. (2005) A Gravity Model of Legal Migration to the United States, Western Illinois University (mimeo).

Mundell, R. (1957) International trade and factor mobility, American Economic Review, 47, 32135.

Polgreen, L. and Simpson, N. (2006) Recent trends in the skill composition of legal U.S. immigrants, Southern Economic Journal, 72, 938-57.

Roy, A. (1951) Some thoughts on the distribution of earnings, Oxford Economic Papers, 3, 13546. 
TABLE 1

\section{Summary Statistics for Education of Immigrants by Country of Origin}

\begin{tabular}{|c|c|c|c|c|c|c|c|c|}
\hline \multirow[t]{2}{*}{ Region } & \multirow{2}{*}{$\begin{array}{l}\text { Immigrants' } \\
\text { Countries of Origin }\end{array}$} & \multirow{2}{*}{$\begin{array}{l}\text { Number of } \\
\text { Immigrants }\end{array}$} & \multicolumn{4}{|c|}{$\begin{array}{l}\text { Constructed Immigrants' } \\
\text { Years of Education }\end{array}$} & \multicolumn{2}{|c|}{$\begin{array}{l}\text { Country of Origin } \\
\text { Ave. Education }\end{array}$} \\
\hline & & & Mean & S.D. & Min & Max & 1960 & 2000 \\
\hline Afr. & Algeria & 2,019 & 14.12 & 2.15 & 9.17 & 18.73 & 0.97 & 4.72 \\
\hline Afr. & Botswana & 37 & 14.18 & 1.92 & 10.96 & 18.16 & 1.46 & 5.35 \\
\hline Afr. & Cameroon & 1,429 & 13.82 & 2.11 & 9.76 & 18.72 & 1.37 & 3.17 \\
\hline Afr. & Congo & 53 & 14.13 & 1.94 & 11.16 & 18.48 & 1.93 & 4.68 \\
\hline Afr. & Egypt & 16,167 & 14.39 & 2.24 & 9.15 & 19.52 & 1.32 & 5.05 \\
\hline Afr. & Gambia & 463 & 12.72 & 1.62 & 9.59 & 18.43 & 0.50 & 1.86 \\
\hline Afr. & Ghana & 10,466 & 12.96 & 1.94 & 9.40 & 19.08 & 0.69 & 4.01 \\
\hline Afr. & Kenya & 4,211 & 13.85 & 1.97 & 9.70 & 18.66 & 1.20 & 3.99 \\
\hline Afr. & Liberia & 4,079 & 12.99 & 1.98 & 9.12 & 19.08 & 0.56 & 2.26 \\
\hline Afr. & Malawi & 214 & 13.98 & 2.10 & 10.62 & 18.62 & 1.70 & 2.58 \\
\hline Afr. & Mali & 295 & 12.56 & 1.65 & 10.57 & 18.48 & 0.17 & 0.76 \\
\hline Afr. & Mozambique & 245 & 12.89 & 1.77 & 10.46 & 18.61 & 0.26 & 1.19 \\
\hline Afr. & Niger & 602 & 13.63 & 2.23 & 9.52 & 18.56 & 0.20 & \\
\hline Afr. & Senegal & 1,173 & 12.83 & 1.69 & 9.47 & 18.42 & 1.60 & 2.23 \\
\hline Afr. & Sierra Leone & 3,425 & 13.07 & 1.86 & 9.30 & 18.73 & 0.53 & 1.99 \\
\hline Afr. & South Africa & 8,928 & 14.36 & 1.84 & 9.50 & 18.75 & 4.08 & 7.87 \\
\hline Afr. & Sudan & 3,439 & 12.92 & 2.12 & 9.45 & 18.93 & 0.29 & 1.91 \\
\hline Afr. & Togo & 316 & 12.94 & 1.95 & 10.32 & 18.57 & 0.32 & 2.83 \\
\hline Afr. & Tunisia & 920 & 13.92 & 1.98 & 9.77 & 18.93 & 0.54 & 4.20 \\
\hline Afr. & Uganda & 1,812 & 13.78 & 2.02 & 9.60 & 18.64 & 1.10 & 2.95 \\
\hline Afr. & Zaire & 844 & 13.12 & 2.02 & 9.77 & 18.50 & 0.56 & 3.18 \\
\hline Afr. & Zambia & 693 & 14.32 & 1.80 & 10.40 & 18.55 & 1.60 & 5.43 \\
\hline Afr. & Zimbabwe & 1,237 & 14.22 & 1.77 & 10.08 & 18.83 & 1.54 & 4.88 \\
\hline Asia & Bahrain & 144 & 14.55 & 1.78 & 11.00 & 18.55 & 1.37 & 6.09 \\
\hline Asia & Cyprus & 889 & 13.95 & 2.04 & 9.66 & 18.65 & 4.29 & 8.77 \\
\hline Asia & Hong Kong & 33,212 & 13.70 & 1.66 & 9.57 & 19.43 & 4.74 & 9.47 \\
\hline Asia & India & 110,804 & 14.33 & 2.33 & 8.73 & 19.92 & 1.45 & 4.77 \\
\hline Asia & Indonesia & 6,260 & 13.80 & 1.84 & 9.57 & 19.18 & 1.11 & 4.71 \\
\hline Asia & Iran & 38,431 & 13.54 & 2.11 & 8.93 & 19.57 & 0.63 & 4.66 \\
\hline Asia & Israel & 11,945 & 13.94 & 2.00 & 9.48 & 19.18 & 6.99 & 9.23 \\
\hline Asia & Japan & 19,689 & 13.58 & 1.69 & 9.54 & 19.33 & 6.87 & 9.72 \\
\hline Asia & Jordan & 10,704 & 13.21 & 2.08 & 9.04 & 18.98 & 1.40 & 7.37 \\
\hline Asia & Korea & 41,355 & 13.60 & 2.17 & 9.09 & 19.67 & 3.23 & 10.46 \\
\hline Asia & Kuwait & 918 & 13.84 & 1.89 & 10.80 & 18.46 & 2.59 & 7.05 \\
\hline Asia & Malaysia & 7,065 & 14.00 & 1.85 & 9.84 & 18.70 & 2.34 & 7.88 \\
\hline Asia & Pakistan & 25,114 & 13.82 & 2.44 & 8.97 & 19.72 & 0.63 & 2.45 \\
\hline Asia & Philippines & 178,353 & 13.19 & 2.15 & 8.69 & 19.47 & 3.77 & 7.62 \\
\hline Asia & Singapore & 2,253 & 14.27 & 1.72 & 9.80 & 20.03 & 3.14 & 8.12 \\
\hline Asia & Sri Lanka & 4,477 & 14.20 & 2.11 & 9.85 & 18.98 & 3.43 & 6.09 \\
\hline Asia & Syria & 7,313 & 13.84 & 2.53 & 9.33 & 19.23 & 0.99 & 5.74 \\
\hline Asia & Thailand & 9,438 & 12.98 & 1.73 & 9.06 & 18.78 & 3.45 & 6.10 \\
\hline Asia & Turkey & 9,142 & 13.55 & 2.11 & 8.95 & 19.53 & 2.00 & 4.80 \\
\hline
\end{tabular}


E. Eur. Bulgaria

E. Eur. Former USSR

E. Eur. Hungary

E. Eur. Malta

E. Eur. Poland

E. Eur. Romania

E. Eur. Yugoslavia

N. Am. Canada

N. Am. Costa Rica

N. Am. Dominican Republic

N. Am. El Salvador

N. Am. Guatemala

N. Am. Haiti

N. Am. Honduras

N. Am. Jamaica

N. Am. Mexico

N. Am. Nicaragua

N. Am. Panama

N. Am. Trinidad \& Tobago

N. Am. United States

Ocean Australia

Ocean New Zealand

Ocean Papua New Guinea

S. Am. Argentina

S. Am. Bolivia

S. Am. Brazil

S. Am. Chile

S. Am. Colombia

S. Am. Ecuador

S. Am. Guyana

S. Am. Paraguay

S. Am. Peru

S. Am. Uruguay

S. Am. Venezuela

W Eur. Austria

W Eur. Belgium

W Eur. Denmark

W Eur. Finland

W Eur. France

W Eur. Germany

W Eur. Greece

W Eur. Iceland

W Eur. Ireland

W Eur. Italy

W Eur. Netherlands

W Eur. Norway

W Eur. Portugal

W Eur. Spain

W Eur. Switzerland

\begin{tabular}{|c|c|c|c|c|c|c|}
\hline 5,097 & 13.76 & 2.24 & 9.77 & 18.98 & 6.08 & 9.74 \\
\hline 24,784 & 12.83 & 2.02 & 8.66 & 19.08 & 7.59 & 10.49 \\
\hline 4,713 & 13.32 & 2.20 & 9.11 & 19.47 & 6.65 & 8.81 \\
\hline 279 & 13.36 & 1.90 & 10.27 & 18.56 & 5.64 & 7.57 \\
\hline 80,642 & 12.84 & 2.01 & 9.00 & 19.33 & 6.74 & 9.90 \\
\hline 18,677 & 12.95 & 2.16 & 8.86 & 19.28 & 5.33 & 9.51 \\
\hline 8,047 & 13.09 & 2.23 & 8.94 & 19.08 & 5.08 & 7.48 \\
\hline 55,629 & 14.01 & 1.83 & 9.15 & 19.42 & 8.37 & 11.43 \\
\hline 3,930 & 12.46 & 1.86 & 9.04 & 18.57 & 3.86 & 6.01 \\
\hline 98,132 & 12.15 & 1.82 & 8.54 & 19.18 & 2.38 & 5.17 \\
\hline 62,989 & 11.56 & 0.91 & 8.91 & 18.59 & 1.70 & 4.50 \\
\hline 23,747 & 11.80 & 1.43 & 8.84 & 19.03 & 1.43 & 3.12 \\
\hline 28,665 & 12.07 & 1.80 & 8.58 & 19.87 & 0.70 & 2.67 \\
\hline 17,960 & 11.94 & 1.55 & 9.00 & 19.28 & 1.69 & 4.08 \\
\hline 68,728 & 12.08 & 1.54 & 8.61 & 18.87 & 2.46 & 5.22 \\
\hline 279,495 & 11.55 & 1.08 & 8.50 & 18.72 & 2.41 & 6.73 \\
\hline 26,714 & 11.98 & 1.53 & 8.81 & 18.73 & 2.09 & 4.42 \\
\hline 6,887 & 13.04 & 1.86 & 9.02 & 18.93 & 4.26 & 7.90 \\
\hline 19,863 & 12.56 & 1.75 & 8.60 & 18.83 & 4.19 & 7.62 \\
\hline 295 & 14.19 & 2.09 & 9.54 & 19.23 & 8.66 & 12.25 \\
\hline 8,626 & 14.03 & 1.81 & 9.70 & 18.98 & 9.43 & 10.57 \\
\hline 3,964 & 13.81 & 1.83 & 9.97 & 19.42 & 9.56 & 11.52 \\
\hline 51 & 14.09 & 1.83 & 10.97 & 18.42 & 1.13 & 2.39 \\
\hline 9,471 & 13.74 & 2.13 & 9.02 & 18.93 & 4.99 & 8.49 \\
\hline 4,846 & 12.55 & 1.88 & 9.18 & 19.42 & 4.22 & 5.54 \\
\hline 13,800 & 13.27 & 2.02 & 9.42 & 19.03 & 2.83 & 4.56 \\
\hline 5,812 & 13.03 & 2.01 & 8.96 & 19.33 & 4.99 & 7.89 \\
\hline 38,349 & 11.98 & 1.85 & 9.04 & 19.62 & 2.97 & 5.01 \\
\hline 21,202 & 12.29 & 1.70 & 8.88 & 18.72 & 2.95 & 6.52 \\
\hline 26,979 & 12.32 & 1.75 & 8.98 & 19.13 & 3.50 & 6.05 \\
\hline 1,017 & 12.52 & 1.89 & 9.67 & 18.60 & 3.35 & 5.74 \\
\hline 32,367 & 12.41 & 1.85 & 8.54 & 19.57 & 3.02 & 7.33 \\
\hline 2,236 & 12.77 & 1.97 & 9.62 & 18.78 & 5.03 & 7.25 \\
\hline 7,159 & 13.77 & 2.04 & 9.34 & 19.28 & 2.53 & 5.61 \\
\hline 2,199 & 13.75 & 1.86 & 9.20 & 19.28 & 6.71 & 8.80 \\
\hline 2,342 & 14.27 & 1.88 & 9.65 & 19.47 & 7.46 & 8.73 \\
\hline 2,718 & 13.82 & 1.77 & 9.43 & 18.70 & 8.95 & 10.09 \\
\hline 1,889 & 13.86 & 1.82 & 9.46 & 18.88 & 5.37 & 10.14 \\
\hline 10,837 & 13.90 & 1.79 & 9.54 & 19.23 & 5.78 & 8.37 \\
\hline 23,226 & 13.55 & 1.82 & 8.99 & 19.08 & 8.40 & 9.75 \\
\hline 5,659 & 13.29 & 2.24 & 9.29 & 19.57 & 4.64 & 8.51 \\
\hline 557 & 14.03 & 2.05 & 10.23 & 18.51 & 5.63 & 8.75 \\
\hline 51,564 & 13.03 & 1.73 & 9.27 & 18.83 & 6.45 & 9.02 \\
\hline 9,108 & 13.22 & 2.04 & 8.69 & 18.98 & 4.56 & 7.00 \\
\hline 5,857 & 14.04 & 1.82 & 9.64 & 19.03 & 5.27 & 9.24 \\
\hline 1,989 & 13.85 & 1.73 & 9.89 & 18.68 & 6.11 & 11.86 \\
\hline 10,161 & 11.82 & 1.28 & 9.07 & 19.40 & 1.94 & 4.91 \\
\hline 5,174 & 13.74 & 2.14 & 8.77 & 19.23 & 3.64 & 7.25 \\
\hline 4,014 & 14.04 & 1.83 & 9.46 & 18.59 & 7.30 & 10.39 \\
\hline
\end{tabular}


TABLE 2

Summary Statistics for Explanatory Variables

\begin{tabular}{|c|c|c|c|c|}
\hline Variable & Mean & $\begin{array}{l}\text { Standard } \\
\text { Deviation }\end{array}$ & Minimum & Maximum \\
\hline New Immigrants & 0.657 & 0.475 & & \\
\hline Asia Region & 0.299 & 0.458 & & \\
\hline \multicolumn{5}{|l|}{ Regions } \\
\hline East Europe & 0.082 & 0.275 & & \\
\hline West Europe & 0.080 & 0.271 & & \\
\hline Africa & 0.036 & 0.187 & & \\
\hline Oceania & 0.007 & 0.085 & & \\
\hline South America & 0.094 & 0.292 & & \\
\hline \multicolumn{5}{|l|}{ Visa Classes } \\
\hline Family & 0.658 & 0.474 & & \\
\hline Employment & 0.141 & 0.348 & & \\
\hline \multicolumn{5}{|l|}{ Immigration Reform and Control Act } \\
\hline (IRCA) Amnesty & 0.017 & 0.128 & & \\
\hline "Other" Visa Classes & 0.055 & 0.229 & & \\
\hline Diversity & 0.064 & 0.245 & & \\
\hline \multicolumn{5}{|l|}{ Country of Origin Characteristics } \\
\hline $\ln$ (Population) & 17.180 & 1.601 & 12.429 & 20.688 \\
\hline $\ln$ (Population in 1960) & 8.714 & 1.594 & 4.078 & 12.133 \\
\hline $\ln ($ GDP per capita) & 7.834 & 1.202 & 3.799 & 10.519 \\
\hline Corruption Index & 0.556 & 0.201 & 0.000 & 1.000 \\
\hline $\ln$ (Average Education) & 1.733 & 0.407 & -0.868 & 2.500 \\
\hline $\ln ($ Average Education in 1960) & 1.030 & 0.675 & -1.772 & 2.258 \\
\hline English-Speaking Country of Origin & 0.781 & 0.413 & 0.000 & 1.000 \\
\hline Shared Colonial History (with U.S.) & 0.112 & 0.316 & 0.000 & 1.000 \\
\hline Distance from U.S. (miles) & 7,160 & 4,240 & 1,850 & 1,550 \\
\hline Number of Observations & $1,729,019$ & & & \\
\hline
\end{tabular}


TABLE 3

OLS Results (Dependent Variable $=\ln \left[\right.$ Constructed Immigrant Education]). ${ }^{\text {b }}$

Variable

Constant

New Immigrants

Year

Year $^{2}$

Year $^{3}$

Asia

East Europe

West Europe

Africa

Oceania

South America

Employment

Family

Other

Diversity

IRCA Amnesty

$\ln$ (Population in 1960)

$\ln$ (Population)

$\ln$ (GDP per capita)

English-Speaking

Shared Colonial History

Corruption Index

$\ln$ (Distance from U.S.)

$\ln$ (Ave. Education in 1960)

$\ln$ (Average Education)

Adjusted $R^{2}$

Log-Likelihood
(1)

$-98.913^{* *}(5.558) \quad-85.456^{* *}(5.500)-135.753^{* *}(5.507) \quad 2.638^{* *}(0.050)$

$-0.023^{* *}(0.000) \quad-0.023^{* *}(0.000) \quad-0.022^{* *}(0.000) \quad-0.022^{* *}(0.000)$

$3.244^{* *}(0.180) \quad 2.823^{* *}(0.178) \quad 4.479^{* *}(0.178)$

$-0.035^{* *}(0.002) \quad-0.030^{* *}(0.002) \quad-0.048^{* *}(0.002) \quad 6.30 \mathrm{e}-5^{* *}(0.000)$

$1.22 \mathrm{e}-4^{* *}(0.000) \quad 1.06 \mathrm{e}-4^{* *}(0.000) \quad 1.73 \mathrm{e}-4^{* *}(0.000) \quad-5.68 \mathrm{e}-7^{* *}(0.000)$

$0.105^{* *}(0.000) \quad 0.107^{* *}(0.000) \quad 0.035^{* *}(0.001) \quad 0.034^{* *}(0.001)$

$0.068^{* *}(0.000) \quad 0.001 \quad(0.001) \quad-0.080^{* *}(0.001) \quad-0.080^{* *}(0.001)$

$0.088^{* *}(0.000) \quad 0.024^{* *}(0.001) \quad-0.031^{* *}(0.001) \quad-0.030^{* *}(0.001)$

$0.119^{* *}(0.001) \quad 0.123^{* *}(0.001) \quad 0.057^{* *}(0.001) \quad 0.057^{* *}(0.001)$

$0.124^{* *}(0.001) \quad 0.083^{* *}(0.001) \quad-0.004^{*}(0.002) \quad-0.005^{*}(0.002)$

$0.030^{* *}(0.000) \quad 0.028^{* *}(0.000) \quad 0.000 \quad(0.001) \quad-0.001 \quad(0.001)$

$0.125^{* *}(0.001) \quad 0.111^{* *}(0.001) \quad 0.117^{* *}(0.001) \quad 0.116^{* *}(0.001)$

$0.036^{* *}(0.000) \quad 0.030^{* *}(0.000) \quad 0.040^{* *}(0.000) \quad 0.039^{* *}(0.000)$

$0.064^{* *}(0.001) \quad 0.057^{* *}(0.001) \quad 0.068^{* *}(0.001) \quad 0.068^{* *}(0.001)$

$0.058^{* *}(0.001) \quad 0.049^{* *}(0.001) \quad 0.060^{* *}(0.001) \quad 0.058^{* *}(0.001)$

$0.008^{* *}(0.001)$

$0.007^{* *}(0.001)$

$0.024^{* *}(0.001)$

$0.023^{* *}(0.001)$

$0.077^{* *}(0.000) \quad 0.072^{* *}(0.001) \quad 0.072^{* *}(0.001)$

$-0.074^{* *}(0.000) \quad-0.067^{* *}(0.001) \quad-0.067^{* *}(0.001)$

$-0.002^{* *}(0.000) \quad-0.016^{* *}(0.000) \quad-0.016^{* *}(0.000)$

$0.006^{* *}(0.000) \quad 0.001^{* *}(0.000) \quad 0.001^{* *}(0.000)$

$-0.021^{* *}(0.000) \quad-0.023^{* *}(0.001) \quad-0.024^{* * *}(0.001)$

$0.115^{* *}(0.001) \quad 0.113^{* *}(0.001)$

$0.037^{* *}(0.001) \quad 0.038^{* *}(0.001)$

$-0.007^{* *}(0.001) \quad-0.007^{* *}(0.001)$

$0.029^{* *}(0.001) \quad 0.030^{* *}(0.001)$

$\begin{array}{rrrr}0.188 & 0.205 & 0.216 & 0.216 \\ 983,594 & 1,002,141 & 1,014,200 & 1,013,884\end{array}$

Akaike Info Criterion

${ }^{\text {b }}$ Standard errors in parentheses. ${ }^{*}$ Indicates significance at the $10 \%$ level. ${ }^{* *}$ Indicates significance at the $1 \%$ level. 
TABLE 4

Selected Quantile Regression Results (Dependent Variable = $\ln \left[\right.$ Immigrants’ Education]), Unrestricted Model. ${ }^{\mathrm{b}}$

Variable

Constant

New Immigrants

Year $^{2}$

Year $^{3}$

Asia

East Europe

West Europe

Africa

Oceania

South America

Family

Employment

IRCA Amnesty

Other

Diversity

$\ln ($ Population in 1960)

$\ln$ (Population)

$\ln ($ GDP-per capita)

English-Speaking

Colonial History

$\ln$ (Distance from US)

Corruption Index

$\ln$ (Education in 1960)

$\ln$ (Ave. Education)

Pseudo- $R^{2}$

\begin{tabular}{|c|c|c|c|}
\hline & & & \\
\hline $1.412^{*}$ & $(0.05$ & 1.71 & 0.0 \\
\hline$-0.028^{* *}$ & $(0.000)$ & $-0.026^{* *}$ & $.000)$ \\
\hline $3.84 \mathrm{e}-4^{* *}$ & $(0.000)$ & $3.27 \mathrm{e}-4^{* *}$ & $(0.000)$ \\
\hline $.85 e-6^{* *}$ & $(0.000)$ & $-2.46 \mathrm{e}-6^{* *}$ & $0.000)$ \\
\hline $0.022^{* *}$ & $(0.001)$ & $0.025^{* *}$ & $0.001)$ \\
\hline$-0.023^{* *}$ & $(0.001)$ & $-0.078^{* *}$ & $(0.001)$ \\
\hline $0.003^{* *}$ & $(0.0$ & $-0.036^{* *}$ & 1) \\
\hline $0.065^{* *}$ & $(0.002)$ & $0.051^{* *}$ & (0.001) \\
\hline $0.023^{* *}$ & $(C$ & $0.010^{* *}$ & 1) \\
\hline 0.000 & $(0.001)$ & -0.0 & $(0.000)$ \\
\hline $0.004^{* *}$ & $(0.0$ & $0.024^{* *}$ & 0. \\
\hline $0.042^{* *}$ & $(0.001)$ & $0.087^{* *}$ & (0.000) \\
\hline $0.024^{* *}$ & $(0.001)$ & $0.027^{* *}$ & $(0.0$ \\
\hline 0.001 & $(0.001)$ & $0.024^{* *}$ & (0.000) \\
\hline $0.030^{* *}$ & $(0.001)$ & $0.037^{* *}$ & $(0.000)$ \\
\hline $0.019^{* *}$ & $(0.001)$ & $0.047^{* *}$ & $(0.000)$ \\
\hline$-0.020^{* *}$ & $(0.001)$ & $-0.043^{* *}$ & $(0.000)$ \\
\hline $0.007^{* *}$ & $(0.000)$ & $-0.003^{* *}$ & $(0.000)$ \\
\hline$-0.002^{* *}$ & $(0.000)$ & $0.002^{* *}$ & $(0.000)$ \\
\hline$-0.030^{* *}$ & $(0.001)$ & $-0.048^{* *}$ & (0.000) \\
\hline $0.004^{* *}$ & $(0.001)$ & $0.019^{* *}$ & (0.001) \\
\hline $0.024^{* *}$ & $(0.001)$ & $0.055^{* *}$ & $(0.001)$ \\
\hline $0.011^{* *}$ & $(0.001)$ & $0.009^{* *}$ & $(0.000)$ \\
\hline$-0.012^{* *}$ & $(0.001)$ & $0.009^{* *}$ & $(0.001)$ \\
\hline 0.058 & & 0.061 & \\
\hline
\end{tabular}

\begin{tabular}{|c|c|c|c|c|c|}
\hline \multicolumn{2}{|c|}{0.50} & \multicolumn{2}{|c|}{0.7} & \multicolumn{2}{|c|}{0.95} \\
\hline $2.564^{* *}$ & $(0.037)$ & $4.734^{* *}$ & (0.044) & $4.609^{* *}$ & (0.11 \\
\hline$-0.022^{* *}$ & $(0.000)$ & $-0.013^{* *}$ & $(0.000)$ & $0.007^{* *}$ & $(0.001)$ \\
\hline $.09 \mathrm{e}-4^{* *}$ & $(0.000)$ & $-4.54 \mathrm{e}-4^{* *}$ & (0.000) & $-4.52 \mathrm{e}-4^{* *}$ & $(0.000)$ \\
\hline $68 \mathrm{e}-7^{* *}$ & $(0.000)$ & $3.16 \mathrm{e}-6^{* *}$ & (0.000) & $3.20 \mathrm{e}-6^{* *}$ & $(0.000)$ \\
\hline $0.055^{* *}$ & $(0.001)$ & $0.097^{* *}$ & (0.001) & $0.047^{* *}$ & (0.003) \\
\hline$-0.116^{* *}$ & $(0.001)$ & $-0.063^{* *}$ & (0.001) & $-0.049^{* *}$ & (0.003) \\
\hline$-0.034^{* *}$ & $(0.001)$ & $-0.008^{* *}$ & (0.001) & $-0.049^{* *}$ & 02) \\
\hline $0.068^{* *}$ & $(0.001)$ & $0.120^{* *}$ & (0.001) & $0.049^{* *}$ & (0.003) \\
\hline $0.006^{* *}$ & $(0.0$ & $0.027^{* *}$ & 0.0 & $-0.031^{* *}$ & (0. \\
\hline$-0.021^{* *}$ & $(0.000)$ & $0.051^{* *}$ & $(0.001)$ & $0.051^{* *}$ & $(0.002)$ \\
\hline $0.043^{* *}$ & $(0.00$ & $0.033^{* *}$ & $(0$. & $0.045^{* *}$ & ( \\
\hline $0.150^{* *}$ & $(0.000)$ & $0.106^{* *}$ & $(0.000)$ & $0.082^{* *}$ & $(0.001)$ \\
\hline $0.049^{* *}$ & $(0.00$ & $0.015^{* *}$ & $(0$. & $-0.090^{* *}$ & $(0$. \\
\hline $0.082^{* *}$ & $(0.000)$ & $0.068^{* *}$ & (0.001) & $0.035^{* *}$ & $(0.002)$ \\
\hline $0.069^{* *}$ & $(0.000)$ & $0.052^{* *}$ & $(0.0$ & $0.031^{* *}$ & $(0.002)$ \\
\hline $0.085^{* *}$ & $(0.000)$ & $0.116^{* *}$ & (0.000) & $0.111^{* *}$ & $(0.001)$ \\
\hline$-0.077^{* *}$ & $(0.000)$ & $-0.115^{* *}$ & $(0.0$ & $-0.110^{* *}$ & $(0.001)$ \\
\hline$-0.020^{* *}$ & $(0.000)$ & $-0.031^{* *}$ & (0.000) & $-0.018^{* *}$ & (0.001) \\
\hline $0.009^{* *}$ & $(0.00$ & $-0.009^{* *}$ & (0.000) & $0.004^{* *}$ & (0.001) \\
\hline$-0.015^{* *}$ & $(0.00$ & $-0.007^{* *}$ & $(0.000)$ & $-0.023^{* *}$ & (0.001) \\
\hline $0.031^{* *}$ & $(0.00$ & $0.027^{* *}$ & (0.001) & $0.052^{* *}$ & $(0.002)$ \\
\hline $0.108^{* *}$ & $(0.001)$ & $0.165^{* *}$ & (0.001) & $0.169^{* *}$ & $(0.002)$ \\
\hline$-0.007^{* *}$ & $(0.000)$ & $-0.013^{* *}$ & (0.000) & $-0.036^{* *}$ & $(0.001)$ \\
\hline $0.041^{* *}$ & $(0.001)$ & $0.051^{* *}$ & (0.001) & $0.010^{* *}$ & $(0.002)$ \\
\hline 0.177 & & 0.180 & & 0.084 & \\
\hline
\end{tabular}


TABLE 5

Ordered Probit Results $(\text { Dependent Variable }=\text { Skill Category })^{\mathrm{b}}$

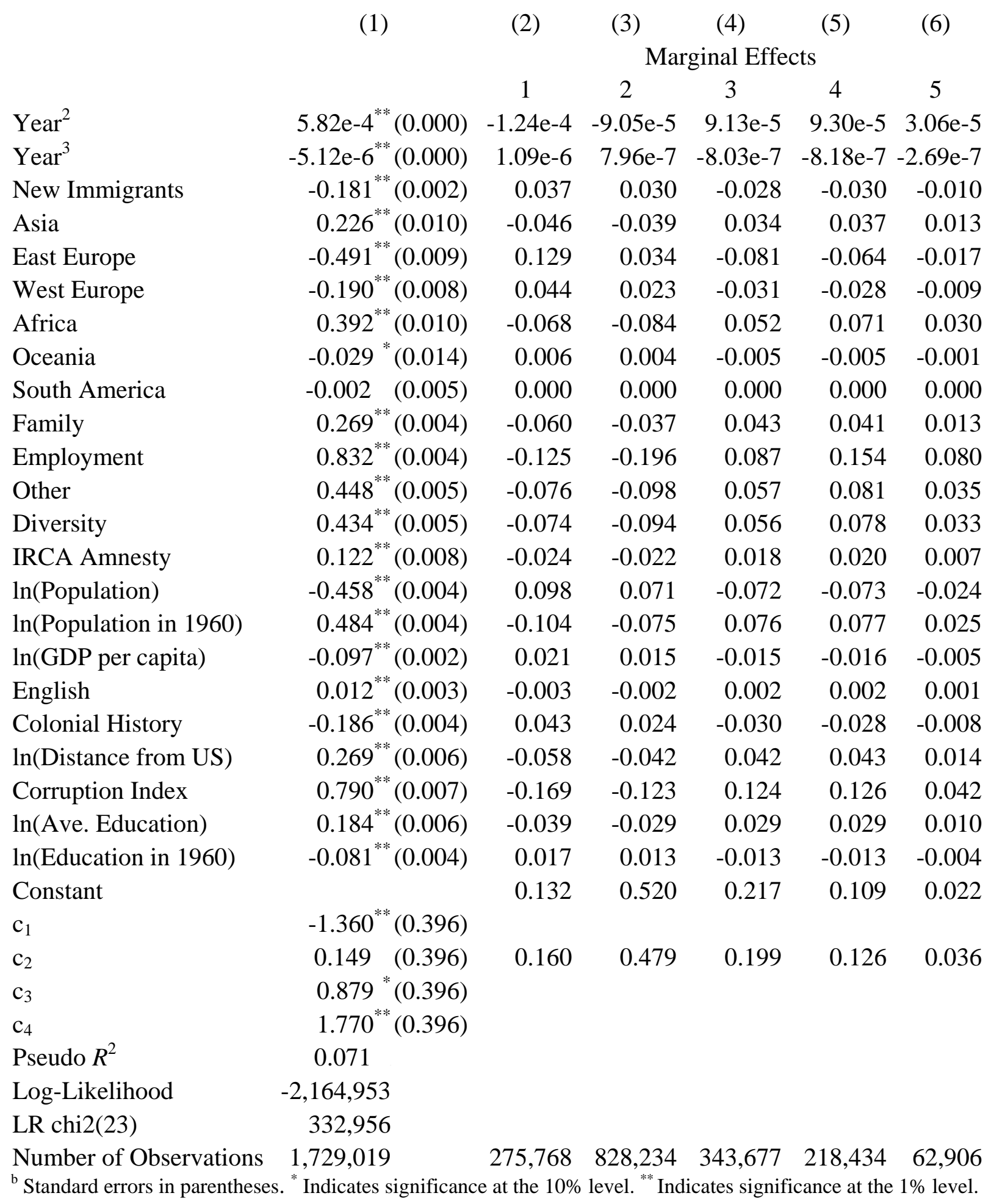


FIGURE 1

Coefficient on Impact of Corruption Index of Immigrants' Country of Origin on the Log of Immigrants' Education vs. Quantile

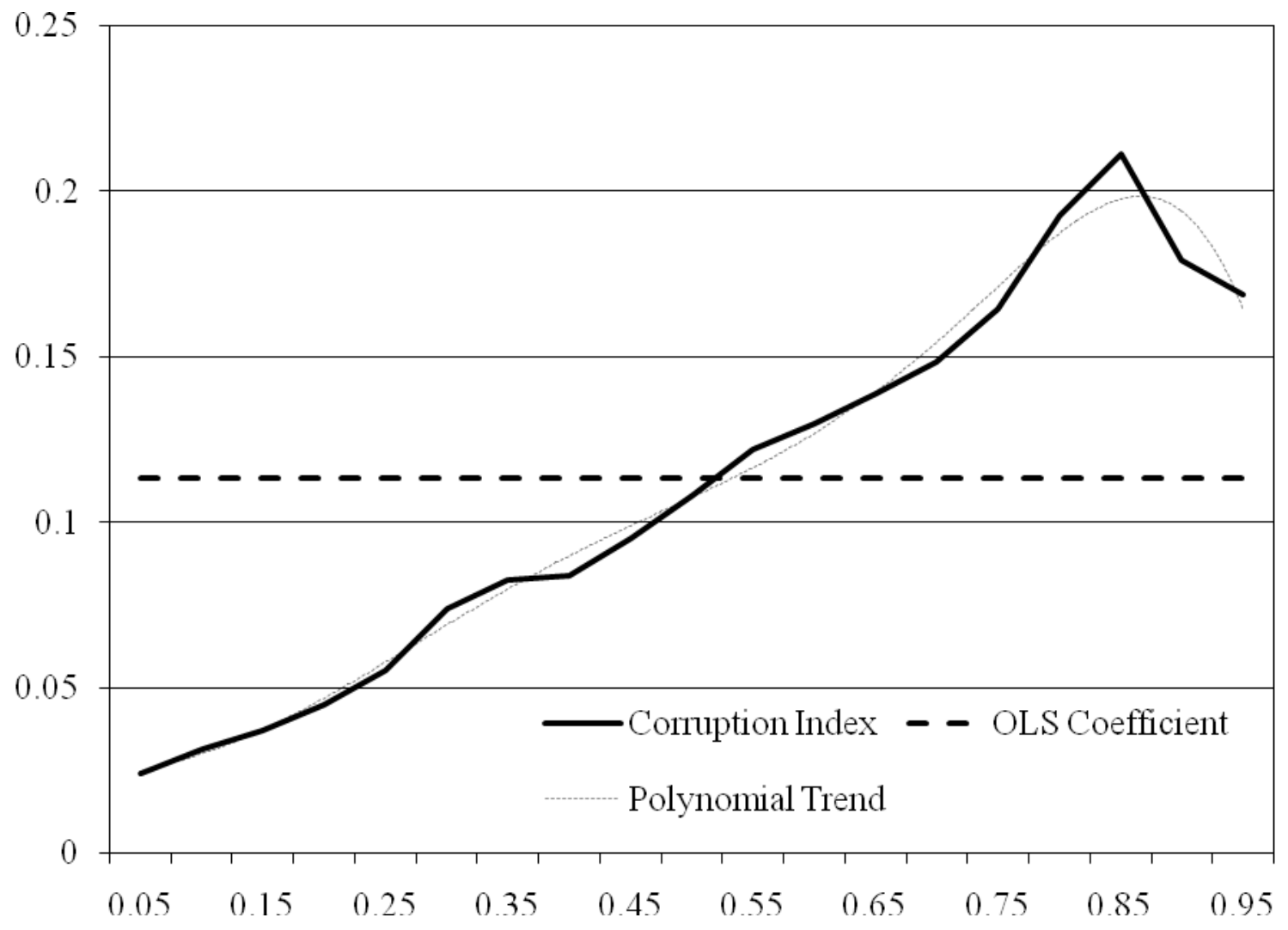


FIGURE 2

Elasticity of Immigrants' Education with Respect to Distance of their Country of Origin from the U.S. vs. Quantile

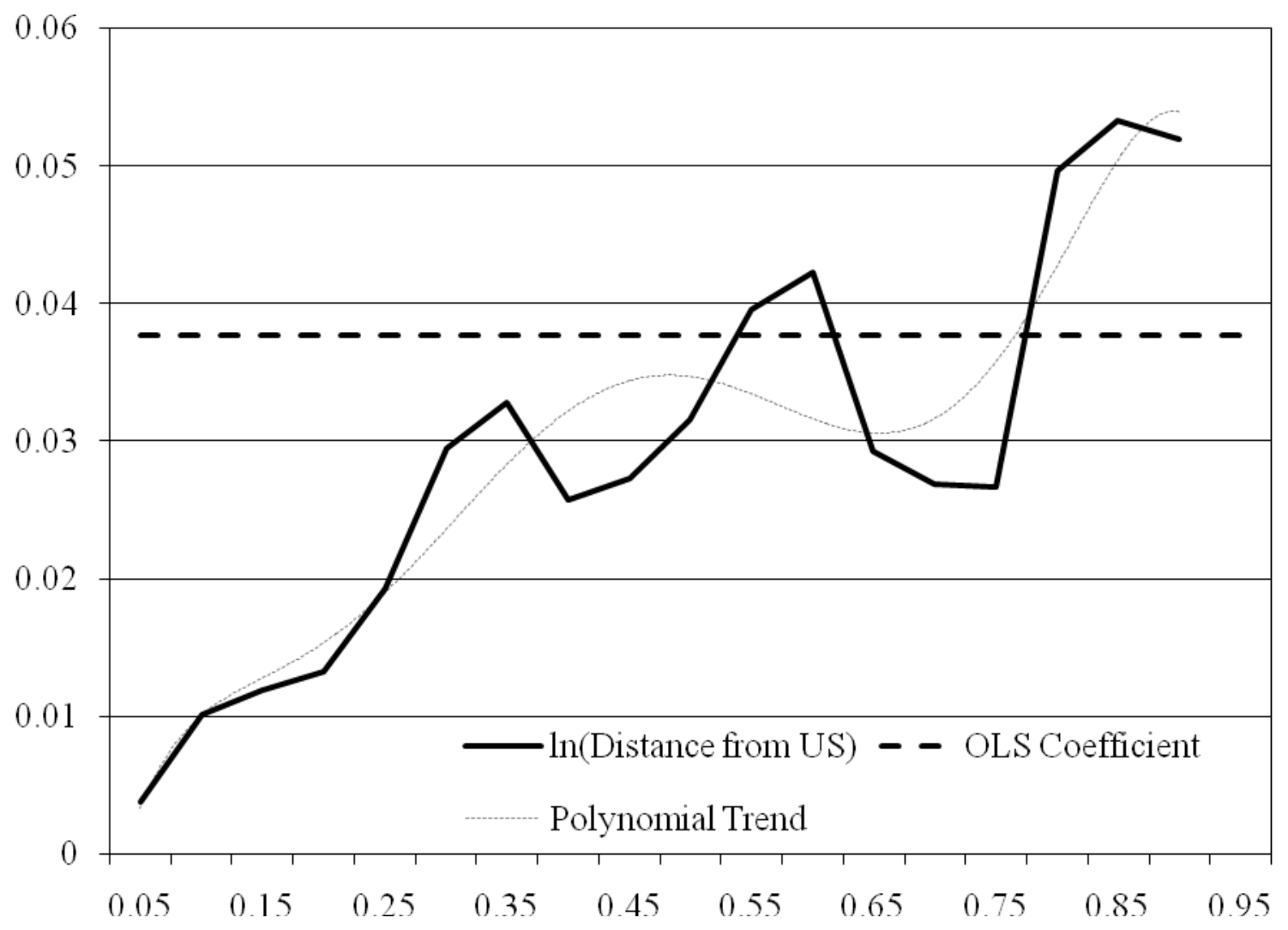


FIGURE 3

Elasticity of Immigrants' Education with Respect to Average Education in their Countries of Origin in 1960 vs. Quantile

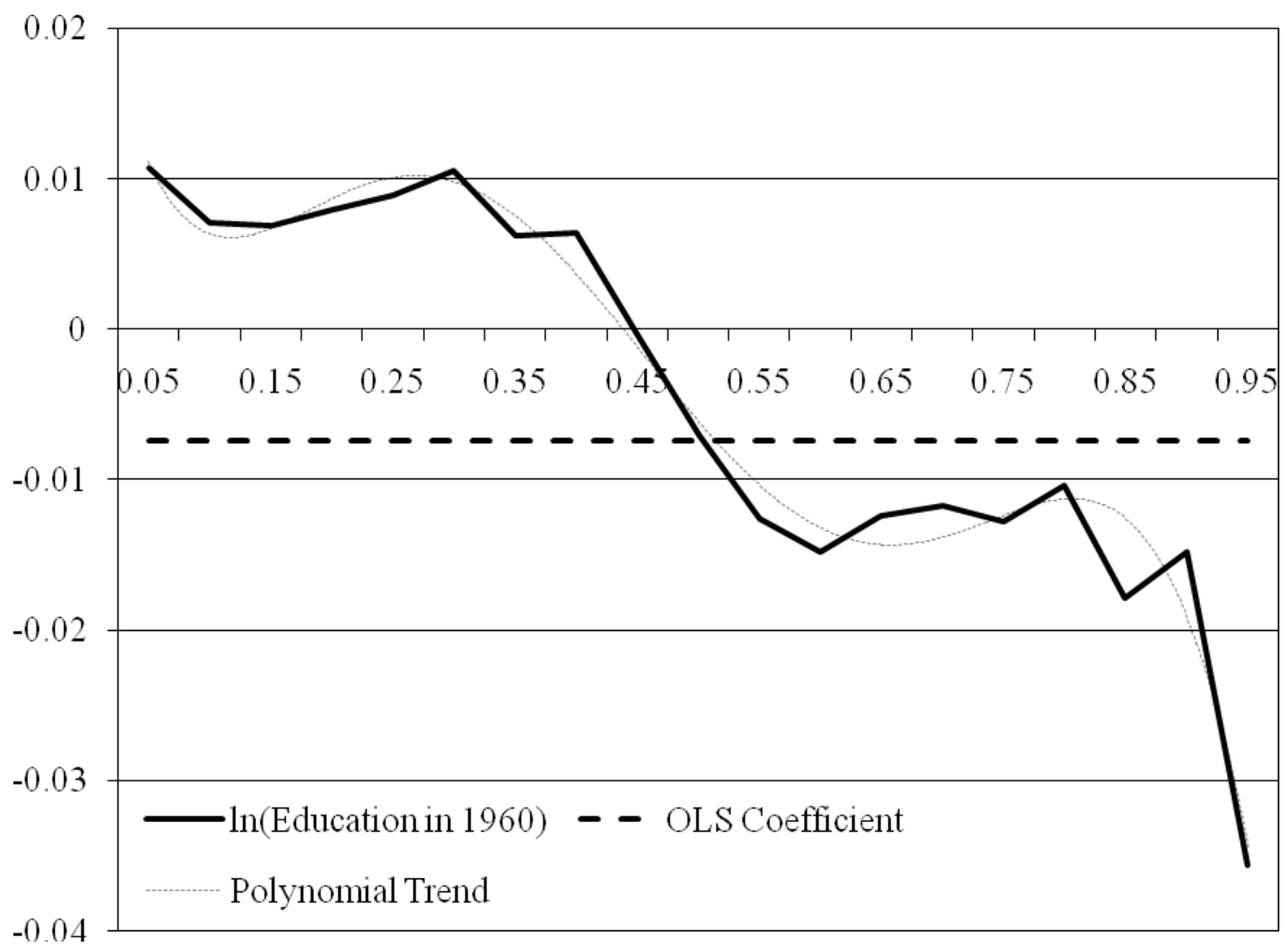


FIGURE 4

Elasticity of Immigrants' Education with Respect to Average Education in their Countries of Origin vs. Quantile

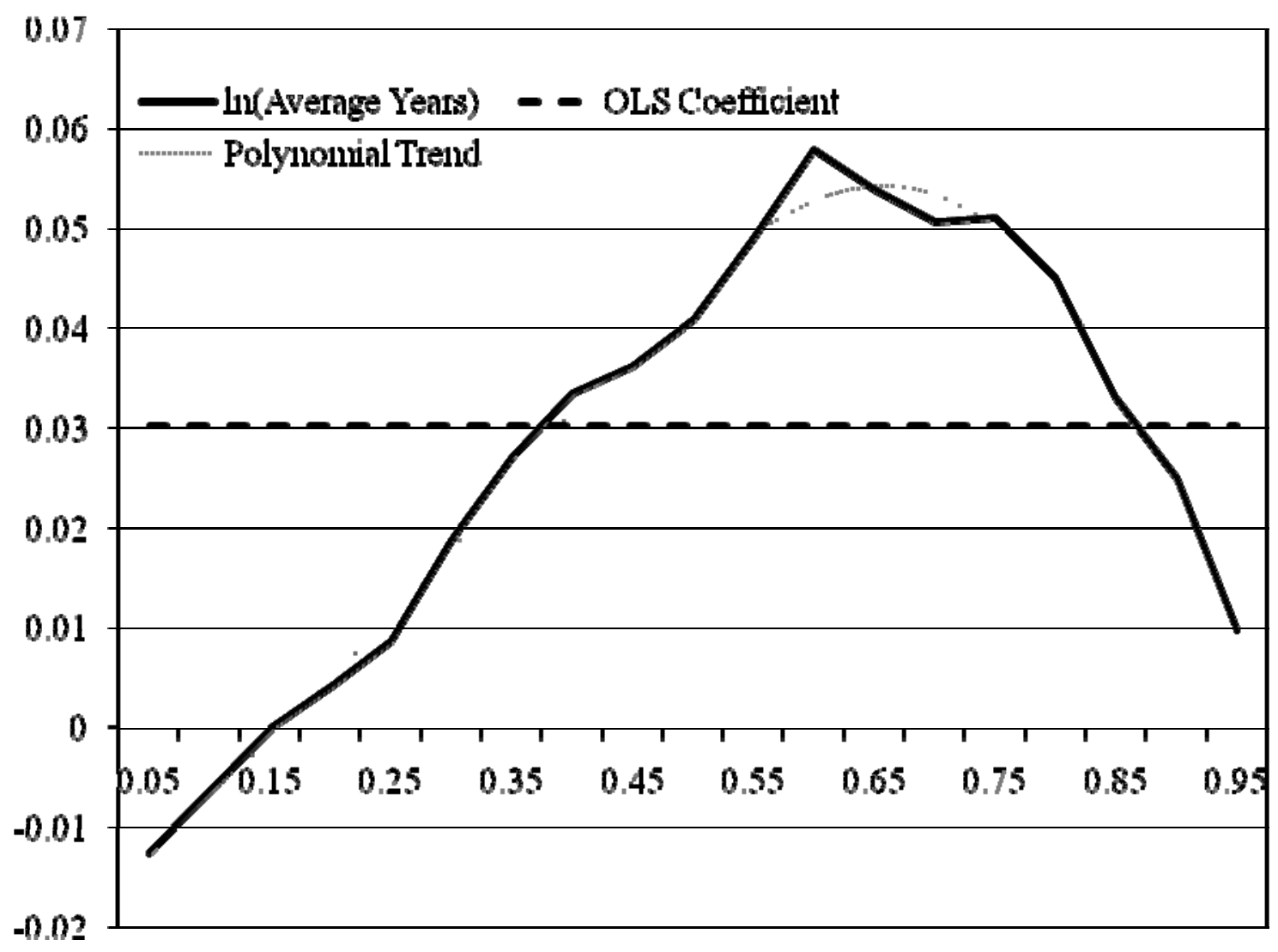

